\title{
ge
}

\section{A CARTOGRAFIA DA CONQUISTA: A FUNÇÃO DOS MAPAS COMO INSTRUMENTO DE LEGITIMAÇÃO DAS CONQUISTAS GEOPOLÍTICAS NO ESPAÇO IBÉRICO DURANTE O ALVORECER DA IDADE MODERNA}

\author{
Alisson Eugênio ${ }^{1}$ \\ Universidade Federal de Alfenas
}

Enviado em 30 jul. 2019 | Aceito em 1 abr. 2021

Resumo: A interdisciplinaridade entre Geografia e História tem se revelado cada vez mais frutífera, gerando progressivamente relevantes resultados, principalmente quando lidam com temas de intensa interface, como a geopolítica, a partir da qual o campo de estudos cartográficos e o da historiografia política associados permitem, por exemplo, compreender os mapas como instrumento de legitimação de conquistas e de ponto de partida para a territorialização. Desse modo, partindo da premissa de que a Cartografia, mais do que representar o espaço, pode também, entre outras funções, servir como um modo não verbal de narrativa histórica, neste artigo será mostrado de que maneira a produção cartográfica ibérica, com ênfase na experiência portuguesa, foi utilizada nos embates geopolíticos do espaço colonial para validar o direito de posse no processo de formação dos impérios ultramarinos no alvorecer da Idade Moderna.

Palavras-chave: cartografia, conquista geopolítica e formação dos impérios coloniais ibéricos.

\section{THE CARTOGRAPHY OF THE CONQUEST: THE FUNCTION OF MAPS AS AN INSTRUMENT OF LEGITIMATION OF GEOPOLITICAL CONQUESTS IN THE IBERIAN SPACE DURING THE DAWN OF THE MODERN AGE}

Abstract: The interdisciplinarity between Geography and History has proven increasingly fruitful, progressively generating relevant results, especially when dealing with topics of intense interface, such as geopolitics, from which the field of cartographic studies and the associated field of political historiography allow, for example, to understand maps as an instrument of legitimation of conquests and the starting point for territorialization. Thus, based on the premise that cartography, more than representing space, can also, among other functions, serve as a non-verbal mode of historical narrative, this article will show how the Iberian cartographic production, with emphasis on the Portuguese experience, was used in geopolitical clashes of the colonial space to validate the right of possession in the process of formation of overseas empires at the dawn of the Modern Age.

Keywords: cartography, geopolitical conquest and formation of Iberian colonial empires.

\section{LA CARTOGRAFÍA DE LA CONQUISTA: LA FUNCIÓN DE LOS MAPAS COMO INSTRUMENTO DE LEGITIMACIÓN DE LAS CONQUISTAS GEOPOLITICAS EN EL ESPACIO IBÉRICO DURANTE LOS ALBORES DE LA EDAD MODERNA}

Resumen: La interdisciplinariedad entre la Geografía y la Historia ha sido cada vez más fructífera, generando progresivamente resultados relevantes, especialmente cuando se tratan temas de intensa interfase, como la geopolítica, a partir de la cual el campo de los estudios cartográficos y el campo de la historiografía política permiten, por ejemplo, entender los mapas como instrumento de legitimación de conquistas y punto de partida para la territorialización. Así, partiendo de la premisa de que la Cartografía, más que representar el espacio, puede también, entre otras funciones, servir como modo no verbal de narración histórica, este artículo mostrará cómo la producción cartográfica ibérica, con énfasis en la experiencia portuguesa, fue utilizada en los enfrentamientos geopolíticos del espacio colonial para validar el derecho de posesión en el proceso de formación de los imperios de ultramar en los albores de la Edad Moderna.

Palabras clave: cartografía, conquista geopolítica y formación de imperios coloniales ibéricos.

1. Professor de História do Brasil na Universidade Federal de Alfenas. Doutor em História Econômica pela Universidade de São Paulo. ORCID: http://orcid.org/0000-0003-4294-2568. E-mail: alissoneugenio@yahoo.com.br. 
Introdução

Sabe-se que os mapas, como uma forma de linguagem não verbal, exercem desde os primórdios da civilização a relevante função de representar a relação humana com o espaço. Desse modo, depois de terem cumprindo o papel original para o qual foram produzidos, constituem rico material documental, como mostra Quadros (2008), para diversos tipos de estudo, especialmente os que têm como tema as tensões geopolíticas abordadas pelo viés, reafirmado por Jacob (2016), do que se conhece como história cultural da cartografia.

Além disso, eles também podem ser tomados como objeto de pesquisa, e dessa maneira, muito podem contribuir, por exemplo, para elucidar problemas históricos fundamentais para o entendimento da motivação e solução de conflitos inerentes à formação territorial e à configuração socioespacial em todo o planeta.

Para tanto, muito tem contribuído a superação da visão da produção cartográfica como uma estrutura unívoca, objetiva e neutra, ao abrir a possibilidade de sua compreensão como um artefato resultante de relações dialéticas complexas derivadas da experiência social.

Um dos teóricos que vêm atuando nessa direção é John Brian Harley. De acordo com ele, os mapas são

una construcción social del mundo expresada a través del medio de la cartografía. Lejos de fungir como una simple imagen de la naturaleza que puede ser verdadera o falsa, los mapas redescriben el mundo, al igual que cualquier otro documento, en términos de relaciones y prácticas de poder, preferencias y prioridades culturales. Lo que leemos en un mapa está tan relacionado con un mundo social invisible y con la ideología como con los fenómenos vistos y medidos en el paisaje. Los mapas siempre muestran más que la suma inalterada de un conjunto de técnicas (HARLEY, 2005, p. 61).

Em outras palavras, conforme ele reafirma em outra publicação, os mapas são muito mais do que meros "levantamentos inertes de paisagens morfológicas ou reflexos passivos do mundo dos objetos", pois, uma vez que as suas imagens são construções sociais expressadas através de uma linguagem cartográfica, eles "contribuem para o diálogo num mundo socialmente construído, e como tal, assim como outras formas de representação não verbal, necessitam ser decodificados" (HARLEY, 2009, p. 2).

Em relação às questões específicas das tensões geopolíticas, outro teórico, Antonio Sánchez, que muito contribui para superação da visão dos mapas apenas como uma representação neutra do espaço, argumenta que, ao serem interpretados como uma construção resultante das relações socioespaciais, eles "passam a ser concebidos como metáforas de domínio, controle e poder sobre o mundo, como alegorias imperiais e não somente como imagens físicas de um lugar" (SÁNCHEZ, 2013, p. 40).

Dessa forma, a cartografia pode ser considerada uma modalidade de narrativa não verbal por meio da qual pode-se interpretar como a sua produção, além de representar o espaço, foi motivada para o exercício do poder sobre uma extensão territorial, atuando como uma espécie de panóptico que auxilia no controle e normalização de um recorte, ou divisa, espacial cujo direito de posse buscase legitimar.

Assim, fundamentado nessas considerações iniciais, este estudo será conduzido com o objetivo de compreender os mapas elaborados pelos Estados Modernos ibéricos durante o alvorecer da Idade Moderna como instrumento político de legitimação de seus poderes sobre o espaço conquistado no processo de expansão territorial e de disputas pelas fronteiras coloniais no Novo Mundo. 


\title{
Fundamentos teóricos e metodológicos
}

Seguindo a senda teórica que Harley ajudou a trilhar, para formulação de uma nova abordagem da cartografia histórica, esta pesquisa partirá da sua proposição de que os mapas são imagens que podem ser decodificadas como uma construção textual (HARLEY, 2005, p. 72) para interpretar a produção cartográfica dos Estados Modernos ibéricos, particularmente o português, como uma narrativa histórica de seus embates geopolíticos durante os primórdios da formação de seus impérios coloniais (1415-1580).

Como tal, os mapas devem ser investigados tendo em vista as suas condições políticas de produção, o que demanda a sua contextualização histórica, para a compreensão da sua utilização como instrumento de poder, especificamente o poder de persuasão diplomática, sem o qual a guerra poderia ser inevitável.

Em relação a essa especificidade, para que ela pudesse ser exercida, em uma época desprovida de meios tecnológicos rigorosos de verificação, o modo como os signos espaciais foram cartografados, construindo uma representação convincente do espaço que se procurava territorializar, são determinantes para o cumprimento da sua função legitimadora do direito de posse.

Por isso, é necessário ter em mente um conceito de representação que vai além de uma simples mimese do espaço, para o entendimento da sua dimensão e função como instrumento estratégico na dialética geopolítica que envolveu os Estados nacionais ibéricos nos seus esforços de consolidar o seu poder internacional e seu domínio no Novo Mundo. A esse respeito, eis o que nos esclarece Roger Chartier (2002, p. 17):

\begin{abstract}
As representações do mundo social assim construídas, embora aspirem à universalidade de um diagnóstico fundado na razão, são sempre determinadas pelos interesses de grupo que as forjam. Daí, para cada caso, é necessário relacionamento dos discursos proferidos com a posição de quem os utiliza. As percepções do social não são, de forma alguma, discursos neutros: produzem estratégias e práticas (sociais, escolares, políticas) que tendem a impor uma autoridade à custa de outros, por elas menosprezados. Tendem a legitimar um projeto reformador ou a justificar, para os próprios indivíduos, as suas escolhas e condutas. Por isso, esta investigação sobre as representações supõe-nas como estando sempre colocadas num campo de concorrências e de competições cujos desafios se enunciam em termos de poder e dominação. As lutas de representações têm tanta importância como as lutas econômicas para compreender os mecanismos pelos quais um grupo impõe, ou tenta impor, a sua concepção do mundo social, os valores que são seus, e o seu domínio.
\end{abstract}

Tal conceito, assim formulado, nos permite entender que a elaboração dos mapas, sendo, nos termos de Harley (2005, p. 61), "uma construção social do mundo expressada através da cartografia", não está imune a ideologias, interesses e manipulações políticas.

Então, como uma construção social, a produção cartográfica é, como outras produções socialmente construídas, uma prática cultural dotada, conforme entendimento de Harley (2005, p. 63), "de uma dimensão simbólica", cujos códigos constituidores de uma retórica imagética formadora do discurso iconográfico podem ser interpretados a partir do conceito de cultura proposto por Clifford Geertz (1978, p. 15): um sistema simbólico por meio do qual a ação humana, em suas mais diversas interações, pode ser compreendida como um signo, cujo significado depende das suas conexões com o contexto no qual está inserido e com a multiplicidade de estruturas que possibilitaram a sua ocorrência.

Em termos metodológicos, transportando essa premissa para a produção cartográfica na época em análise neste artigo, os mapas serão doravante interpretados como uma prática cultural 
composta por teia de significados, por meio das quais os indivíduos e as coletividades nas quais estão inseridos revelam suas percepções e as ações delas decorrentes sobre o mundo.

Dessa maneira, a cartografia produzida no contexto das disputas territoriais no espaço ibérico durante o alvorecer da Idade Moderna contribui para revelar como os Estados nacionais ibéricos, motivados por ambições expansionistas, concebiam o mundo em termos geog ráficos e políticos e, a partir dessa concepção, organizaram suas atuações no cenário internacional.

Tendo feitos esses esclarecimentos teóricos, em seguida será feita uma exposição da experiência histórica do Estado português para contextualizar a sua produção cartográfica e mostrar como ela foi direcionada para cumprir a função de orientar o seu expansionismo e de legitimar suas conquistas.

\section{A reconfiguração da imagem do mundo: o vanguardismo português}

A expansão marítima portuguesa foi inaugurada com a tomada de Ceuta em 1415. Para os especialistas, como Barreto (1983), esse êxito primordial foi possível graças a um conjunto de fatores, tais como: a vontade política dos seus soberanos, os seus investimentos em estudos de navegação, representados pela até hoje muito celebrada Escola de Sagres, a posição geográfica favorável de Portugal, as novidades técnicas, que diminuíram as dificuldades das viagens marítimas, que criaram as condições para a formação do que Dutra (2013) chamou de "cultura do descobrimento."

Todavia, esse conjunto de fatores foi, segundo Boxer (2012, p. 33), precedido por motivações religiosas de um Reino que se formou no entrópico quadro da Reconquista cristã da Península Ibérica. Terminada essa empreitada, tempos depois, em face dos receios de uma nova invasão islâmica no seu território, e do sentimento cruzadista herdado da época medieval, suas lideranças resolveram atacar o inimigo na sua própria casa.

Além disso, conforme esclarece Alencastro (1998, p. 193-207), deve-se considerar outro fator motivacional muitas vezes ignorado, qual seja, o fato de que os portugueses nasceram e viveram por quase a metade da Baixa Idade Média e início da Idade Moderna sob pressão política de Castela, sobretudo após os problemas de sucessão que culminaram no fim da dinastia da casa de Borgonha e da ascensão da casa Avis com controversa aclamação de João I em 1385, como novo rei de Portugal, por meio de uma guerra civil conhecida como Revolução de Avis.

Com essa aclamação a nova dinastia, em um cenário de fortes instabilidades e de apreensões, promoveu um expansionismo, como forma angariar apoio dos que a ela se opunham, objetivando conquistar territórios além-mar, uma vez que sua posição geográfica, entre o oceano e os reinos que integravam o restante da península, não Ihe deu outra saída para evitar conflito com outros povos cristãos, a não ser o mar e a guerra contra os que a cristandade considerava como "infiéis."

Sobre isso, Thomaz (1998, p. 60) acrescenta que, se a religião foi o grande fator motivacional do projeto expansionista empreendido pela nova casa reinante, não se pode ignorar que ela acabou sendo a justificativa mais conveniente e estrategicamente justificada para melhorar a imagem que os portugueses haviam construído de um governo encabeçado por um rei bastardo que havia chegado ao poder depois de uma guerra.

Diante do exposto, pode-se dizer que os fatores são muitos e imbricados, principalmente no que diz respeito à necessidade de legitimação da nova casa monárquica e o sentimento cruzadista que animou o espírito expansionista português, que em 1415, três décadas após a aclamação de D. João I, já havia conseguido, sob a liderança desse monarca, conquistar da cidade marroquina de Ceuta; ponto estratégico na comunicação entre a África e a Europa. 
Sendo assim, tal conquista é celebrada, no plano da mitologia política portuguesa, como marco simbólico da sua expansão ultramarina, apesar das divergências historiográficas atuais que tem uma visão mais crítica em relação aos historiadores do século XIX, que analisavam tal evento a partir de uma perspectiva nacionalista, engrandecendo os feitos realizados pelos portugueses e minimizando as consequências negativas da expansão; perspectiva que ao longo do século XX continuou sendo utilizada para a formação da consciência histórica de tal país, apesar do surgimento de novas abordagens que, ao fazerem a opção por ótica sociológica da história, criticam a abordagem teleológica a respeito da tomada de Ceuta, como esclarece Thomaz (1998, p. 21), para quem tal tomada se "não houvesse seguido a dezenove anos de distância à passagem do Bojador, por certo, que ninguém se lembraria de ver nela mais que uma das várias manifestações do movimento de mutação do equador religioso que era o Mediterrâneo."

Seja como for, não resta dúvida de que, ocupando a posição de primeiro êxito expansionista na ordem das conquistas que impulsionaram expansão marítima portuguesa, a tomada de Ceuta abriu novas possibilidades para o pequeno reino de Portugal reconfigurar os mapas que davam conta de representar parte do mundo até então conhecido. Em relação a isso, Serrão (1995, p. 15), um dos autores mais versados nesse tema, afirma que conquista de Ceuta se reveste de grande importância histórica porque incentivou a continuidade dos empreendimentos expansionistas ao abrir duas vertentes de expansão: "a primeira com a exploração da costa ocidental da África e a segunda com o descobrimento e colonização dos arquipélagos do Atlântico."

Enfim, a tomada de Ceuta foi, para os interesses expansionistas portugueses, como a transposição do Rubicão por César (um caminho sem volta, ou uma decisão da qual não se podia voltar atrás) para a ocupação de Roma. Ela não só proporcionou, inicialmente, a posse de um território, estratégico para dar sequência a novos empreendimentos de igual natureza, e o impulso catalizador que contribuiu para reforçar a motivação psicológica de um Reino (fiel à cultura de valorização da conquista sobre a qual estava fundamentada a nobreza hereditária) em busca de dilatação do seu espaço, da sua fé e do seu prestígio, mas também, posteriormente, o controle das rotas marítimas de comércio entre o Atlântico e o Levante.

Para isso, conforme sintetiza Vitorino Magalhães Godinho (2007) ao longo do seu trabalho, foi decisiva a atuação do Infante D. Henrique, quinto filho de D. João I. Atribui-se a ele o convencimento decisivo para seu pai organizar a expedição que proporcionou a posse de Ceuta, bem como a articulação política, o financiamento e a organização de expedições que consolidaram a presença portuguesa na África e o controle de arquipélagos atlânticos, como os Açores e a Madeira, razão pela qual foi consagrado com a lendária alcunha de "Henrique o navegador" da prestigiada Escola de Sagres. Igualmente decisiva foi a atuação de D. Afonso V, primo de D. Henrique, cujo reinado foi em grande parte dedicado às investidas militares das praças marroquinas de Alcácer Ceguer (1458), Arzila e Tânger (1471), o que franqueou parte do norte africano e o acesso à Costa da Mina aos portugueses, incrementando "o período áureo dos feitos militares além-estreito" (GODINHO, 2007, p. 198).

Ao longo da mesma síntese Godinho (2007) destaca os esforços de D. João II, sucessor D. Afonso $\mathrm{V}$, pelo fato de seu governo ter se empenhado para impulsionar as viagens marítimas das quais resultaram diversas conquistas, bem como para as negociações, para as quais foi decisiva a produção cartográfica, que levaram ao Tratado de Tordesilhas (1494).

A assinatura desse tratado foi fundamental para o êxito do expansionismo português, porque, com a chegada de Cristóvão Colombo na América em 1492, por uma expedição financiada por Castela, a Coroa portuguesa viu seus interesses ameaçados pelo seu vizinho, a levando no ano seguinte se reunir com a sua rival para rediscutir, sob a tutela do papa Alexandre VI, as áreas de 
atuação de cada uma delas no mundo, o que resultou em 1494 no referido tratado, a partir do qual foi concedido a Portugal o direito sobre todas as terras que fossem descobertas a leste do meridiano de Tordesilhas e também o monopólio comercial entre Índico e o Atlântico Sul.

Assim, ficou aberto o acesso ao sul deste último oceano, de cuja navegação derivou a formação da América portuguesa e a hegemonia espacial necessária para assegurar, por considerável período, o monopólio comercial acima referido e dar continuidade à ambição religiosa de, conforme esclarece Thomas (1998, p. 165), derrotar o islamismo em seu próprio território.

Esses mesos autores também lembram que durante o reinado de D. João II foram adotadas medidas cruciais, como a centralização das expedições marítimas, que aceleraram a reconfiguração da imagem do mundo. Em decorrência delas, o navegador Bartolomeu Dias dobrou pela primeira vez o Cabo das Tormentas em 1488, posteriormente rebatizado de Cabo da Boa Esperança, que deu novo impulso às navegações em direção às Índias, cujos efeitos práticos levaram à destruição da ideia ptolomaica de que a África se unia ao continente asiático, fazendo do oceano Índico um mar fechado.

Com essas realizações, D. João II contribuiu para consolidação das bases do Estado Moderno português, razão pela qual a historiografia portuguesa, sobretudo a composta por autores mais susceptíveis à nostalgia nacionalista, consagrou, quase ao ponto da mitificação, o seu reinado como o período no qual Portugal atingiu o apogeu da política expansionista.

Com a sua morte em 1495, ascendeu ao trono D. Manuel I, cujas ações privilegiaram a expansão para além do oriente, embora ainda pautada em uma política de instalação de feitorias e fortalezas, pelas costas dos continentes alcançados, destinadas respectivamente a sediar o comércio no litoral e a proteger as rotas oceânicas, dada a dificuldade de se aventurar pelo interior, por falta de maior contingente humano e de informações mais precisas para cálculo de risco.

Todavia, com a posse de Afonso de Albuquerque no governo do Estado português na Índia, em 1509 uma nova tendência reorientou a política expansionista portuguesa, a partir da qual a velha política de estabelecimento de feitorias comerciais e de guarnições fortificadas no litoral foi acrescida de investidas militares no oriente, levando a importantes conquistas, como a cidade de Goa.

Com essa nova possessão, aos poucos os portugueses fomentaram novo paradigma de sua presença dos pelo mundo, o que Ihes valeram a abertura de novos horizontes e, consequentemente, nos primeiros anos do século XVI, o acúmulo de grande número de vitórias pelos mares asiáticos, das quais resultaram a dilatação do seu império marítimo que de agora em diante passou a tocar os quatro cantos do mundo.

Dessa maneira, conforme argumenta Thomaz (1998, p. 197), “Albuquerque construiu para D. Manuel um verdadeiro império marítimo na Ásia e deu à presença portuguesa no Oceano Índico a forma definitiva, que se manteria por mais de um século com alterações insignificantes."

Com outras palavras, ele pondera que a ocupação de Goa em nenhum momento representou a intenção de se construir um império territorial, mas sim um processo gradual de incrementar a territorialidade dos diferentes espaços ligados à rede comercial portuguesa, uma vez que tal cidade, dada a sua localização privilegiada, foi inicialmente ocupada para funcionar como uma sede administrativa, "para assegurar a articulação da rede com os espaços abastecedores e consumidores", e desse modo exercer primordialmente "um fim instrumental" (THOMAZ, 1998, 214215).

Tal política de ocupação territorial inaugurada por Afonso de Albuquerque pode ser considerada um dos pilares do novo expansionismo, que orientou nesta matéria o governo de D. João III iniciado em 1502, o qual obteve relevantes conquistas, como Macau, não obstante a conjuntura financeira complicada do Reino precipitada por diversos problemas: seca, peste, altos custos de manutenção do império ultramarino, conflitos religiosos desencadeados pela Reforma, contestação 
de Francisco I de França em relação à divisão do mundo pelos ibéricos, celebrada no Tratado de Tordesilhas, e tensões criadas por Carlos $\vee$ do Sacro Império que colocou em discussão a posse das ilhas Molucas.

Diante desse quadro e em consequência dele, o projeto expansionista de D. João III sofreu significativas alterações, pois a partir dos anos 1530 a manutenção dos territórios portugueses nas Índias começou a se desgastar devido aos altos custos dos investimentos para novas expedições e à dificuldade de recrutamento militar.

Tudo isso contribuiu para a reorientação da expansão marítima portuguesa, que passou a ser muito mais pragmática do que idealista, de modo que o controle das rotas para oriente não foi mais considerado uma estratégia para a conquista de Jerusalém e sim para a salvaguarda dos interesses econômicos lá assentados.

Além disso, diferentemente de seu pai, que não voltou o seu olhar para a América, ele viu no Novo Mundo uma nova alternativa econômica para resolver os problemas da Coroa, dando início à colonização e exploração litorânea da terra descoberta por Pedro Alvares Cabral em 1500, com a criação das capitanias hereditárias e a instauração do governo geral.

Entretanto, enquanto seu governo empenhava-se para colonizar a sua porção territorial americana, a Índia, apesar das adversidades e da reorientação da função estratégica das rotas que a ela levavam, continuava sendo uma miragem, de forma que foi dada continuidade à política de territorialidade iniciada por Afonso de Albuquerque durante o reinado de D. Manuel, sem novos grandes sucessos e o pior, agora com a amarga experiência do enfraquecimento da rota do Cabo.

O mesmo também pode ser dito em relação a outra frente de ambição expansionista, África, onde foram abandonadas diversas cidades fortificadas ao norte, particularmente no Marrocos, em consequência dos cada vez mais elevados custos da sua defesa diante de recorrentes ataques muçulmanos, o que motivou, com a morte de D. João III, o seu sucessor, D. Sebastião, a se empenhar em investidas na região para combater os mouros e disseminar a fé cristã. Pois, o fracasso naquelas centenárias ocupações significava, segundo Ana Buescu (2008, p. 89), o ressentimento de um conjunto de valores que animavam a alma portuguesa desde os primórdios de sua formação forjada nos quadros da Reconquista e de sua separação de Castela.

Cabe lembrar que tal empenho acabou sendo frustrado por sucessivas derrotas e pela a morte inesperada de D. Sebastião em 1578 na batalha de Alcácer-Quibir, quando tinha apenas 24 anos de idade, o que levou ao enceramento da dinastia dos Avis, precipitando uma nova crise de sucessão monárquica e a anexação de Portugal pela Espanha.

Enfim, a síntese acima mostra que os portugueses, entre 1415 e 1580, empreenderam a abertura do oceano e, com ela, acabaram promovendo a reconfiguração da imagem do mundo, ao ampliarem os limites da Terra até então conhecidos pelos europeus, utilizando para isso, conforme expõe Canas ao longo de sua pesquisa (2003), a cartografia como um instrumento estratégico na orientação da sua expansão e na organização dos seus descobrimentos. Dessa foram, eles contribuíram (embora isso não fosse intencional) para inaugurar novas modalidades de comunicação intercivilizacional, criando as condições para a autoafirmação europeia como a civilização dominante frente à realidade natural e humana. Em outras palavras, tomadas de empréstimo de Barreto (1983, p. 10) eles "realizaram a metamorfose do impossível em possível, do desconhecido em conhecido, ao serem os primeiros a, sistematicamente, enfrentar e transformar o obstáculo de silêncio e medo que é o grande mar oceano em via de comunicação planetária". 


\section{Conquistando o mundo com mapas}

A cartografia, como uma forma de representação do espaço, foi um dos primeiros instrumentos utilizados pelo homem para tentar ordenar e estruturar o meio geográfico, ao oferecer aos seus observadores a chance de controlar determinadas partes do mundo, a partir do fornecimento de informações mapeadas dos mais remotos lugares do planeta, que permitiram, no caso dos Estados Modernos, particularmente os ibéricos, a conquista e a gestão de grandes porções de terra além-mar. Por essa razão, Brotton afirma que, ao elaborarem mapas, "os cartógrafos não apenas reproduzem o mundo, eles também o constroem" (2012, p. 14).

Portanto, com a expansão marítima europeia, um mundo novo começou a ser traçado a partir da régua, do esquadro e do compasso de um cosmógrafo, que, muitas vezes, manipulava os atributos cartográficos de acordo com os ideais políticos, religiosos e econômicos de suas Coroas.

Devido isso, os mapas começavam a ser mantidos sob o maior sigilo possível, à medida que as disputas territoriais e os conflitos geopolíticos aumentavam. Por isso, os que foram produzidos para representarem as terras então descobertas foram convertidos em objetos muito cobiçados e valorizados pelos contrabandistas, acirrando, ainda mais, as disputas travadas pelas principais nações, já que os dados por eles revelados eram vitais para o fortalecimento e continuidade do empreendimento colonial, principalmente, dos reinos ibéricos.

Afinal, conforme argumenta Furtado (2017, p. 13), a descoberta e colonização da América trouxeram "o novo para o interior dos mapas, seja na forma de sua produção científica, seja nas informações que passaram a veicular", os tornando um recurso técnico e político estratégico para os interesses dos Estados nacionais, os quais, com a corrida imperial em busca de novas terras, passaram a se interessar ainda mais pelo conhecimento geográfico e pela produção cartográfica fundamentais para sustentar as suas pretensões territoriais e resolver litígios de fronteira.

Por isso, de acordo com Harley (2009, p. 18), possuir o mapa era como possuir a própria terra por ele representada, o que permite compreender, em grande parte, o porquê das monarquias ibéricas terem feito da cartografia uma arma para resolver as suas questões geopolíticas, ao transformarem os mapas em instrumentos jurídicos e de poder que serviram para autenticar e legitimar a posse sobre as áreas descobertas, funcionando desse modo como um instrumento de exercício de poder, pois, quando uma descoberta geográfica era representada cartograficamente, a sua representação expressava (como prática intrínseca à conquista) o domínio sobre o espaço que se procurava territorializar.

Desse modo, conforme argumenta Black ao longo do seu estudo (2005), as cartografia pode ser compreendida como emissora de discursos de intencionalidades, pois buscam reforçar a autoridade desejada em relação ao recorte espacial que se pretendia dominar, constituindo assim um importante meio de legitimação das possessões territoriais, principalmente em uma época na qual na Europa somente eram aceitas provas, juridicamente, para o exercício do direito legítimo de posse se os Estados conseguissem provar, além da ocupação, o seu o pioneirismo na região ocupada por meio de persuasivas produções cartográficas.

Por esse motivo, em um cenário de grandes rivalidades criado pela corrida marítima, as grandes nações envolvidas no processo de dominação do Novo Mundo passaram a utilizar todos os atributos cartográficos em apoio aos seus interesses, uma vez que eles forneciam as melhores condições de se conquistar a vitória no plano diplomático e jurídico.

Atributos (a geometria, os símbolos, as cores, a projeção, enfim, todos os elementos constituídores de um mapa) que, ao serem manipulados para servirem de armas nos conflitos que Chartier (2002, p. 17) chamou de "lutas de representações", foram utilizados pela política colonizadora 
para validar suas conquistas, o que nos permite concluir, utilizando o trabalho de Lestringant (2009) como base, que a cartografia renascentista passou a forjar as fronteiras naturais dispondo do futuro dos povos, remodelando a estrutura dos continentes e controlando calculadamente o espaço

E isso foi possível devido à ruptura dos padrões cosmográficos, pela qual o mundo era representado e compreendido, resultante, entre outros fatores, de uma nova mentalidade cósmica, influenciada pelos avanços científicos do que se convencionou a chamar de Astronomia e pelos princípios capitalistas que então se enraizavam no Ocidente.

Com isso, surge uma nova cosmografia (da qual Cristóvão Colombo foi, do ponto de vista náutico, um dos marcos inaugurais, e Nicolau Copérnico, do ponto de vista erudito, um dos marcos finais) que estimulou a formação de uma cartografia destinada a auxiliar os impérios a planejar suas ações no espaço, fornecendo informações vitais para suas políticas expansionistas e sua administração dos negócios estatais.

Dessa forma, à medida que a economia capitalista, na sua versão mercantil, ia sendo consolidada, ocorre, como explica David Harvey (1992), um inédito fortalecimento da interligação entre o dinheiro, tempo e espaço, sobre a qual se apoiaram os nascentes Estados Modernos e as frações de classe que a ele correspondia, para o exercício do poder em uma nova realidade histórica.

Assim, compreende-se o porquê de a cartografia expressar, naquele período, "as mudanças estruturais de longo prazo que marcaram a passagem do feudalismo ao capitalismo", uma vez que a economia mundial e sua "nova divisão geográfica do trabalho" contaram para sua gestação com a produção cartográfica, o que permite concluir, com as palavras de Harley (2009, p. 8), que,

assim como o relógio, símbolo gráfico da autoridade política central, introduziu a disciplina do tempo nos ritmos dos trabalhadores da indústria, as linhas dos mapas, ditando a nova topografia rural, introduziram uma 'disciplina do espaço.

Dito de outra forma, com as mudanças estruturais que desaguaram no que os historiadores batizaram como Idade Moderna, o planeta passa a ser representado de maneira adaptada às novas estruturas econômicas e políticas que estavam em formação, em uma época em que a noção de espacialidade foi remodelada, devido principalmente aos avanços dos conhecimentos astronômico e geográfico, para que as relações humanas com o espaço pudessem servir de ponto de partida para a produção de mercadorias.

E é isso que possibilita a compreensão de como, com a abertura de novas rotas comerciais e, consequentemente, o acirramento da competição internacional pela incorporação de novos territórios, a produção cartográfica foi aos poucos sendo submetida ao rigor matemático e geométrico, com a redescoberta do sistema de coordenadas geográficas de Ptolomeu no século XV, fundamental para a gestão e o controle do espaço atenderem aos interesses das políticas expansionistas dos Estados Modernos.

Dessa maneira, estavam criadas as condições para os mapas servirem como instrumentos estratégicos na formação dos impérios coloniais, de modo que, muitas vezes, determinados territórios eram reivindicados no papel antes de serem efetivamente ocupados, como por exemplo os situados na porção sul do continente posteriormente denominado de América, como testemunha o Tratado de Tordesilhas assinado entre Portugal e Espanha em 1494.

Então, com base no que foi dito até agora, sobretudo no que diz respeito à discussão sobre a relação entre o poder e o espaço², a cartografia foi transformada, a partir da época renascentista,

2 Foucault foi um dos pensadores que mais se preocupou com a espacialidade do poder. O autor dizia que "seria preciso fazer uma história dos espaços - que seria ao mesmo tempo uma história dos poderes - que estudasse desde grandes 
mais precisamente no alvorecer da Idade Moderna, em uma importante e eficiente fonte de saber e poder, porque o conhecimento gerado pelas produções cartográficas dificilmente estava dissociado das operações de poder dos nascentes Estados Modernos. Sobretudo depois das grandes descobertas, quando os mapas, além de representar territórios, funcionaram como um meio de legitimar a posse sobre eles.

Isso porque, naquela época, as informações extraídas das representações cartográficas apoiavam, sistematicamente, o exercício do poder do Estado, de modo que os elementos cartográficos eram elaborados visando à expansão da nação por ele governada e, principalmente, para serem utilizados como ponto de apoio diplomático na negociação de tratados, em especial sobre os territórios coloniais.

Portanto, é essa "a nova natureza dos mapas", que Harley se empenha para mostrar ao longo do seu estudo, a qual ele sintetiza nesta passagem com a seguinte afirmação: "Tanto na selectividade de seu conteúdo como em seus signos e estilos de representação, os mapas são uma maneira de conceber, articular e estruturar o mundo humano" (2005, p. 80).

\section{As expressões cartográficas do poder na geopolítica dos Estados ibéricos}

Em um cenário cada vez mais competitivo da corrida expansionista durante a época das Grandes Navegações, o conhecimento cartográfico tornou-se um dos principais meios para a construção de um Império Ultramarino. Conscientes dessa importância, as monarquias ibéricas, à medida que os contornos do mundo estavam sendo reconfigurados pelo expansionismo, traçaram diversas estratégias para monopolizar e proteger os seus mapas.

Para tal propósito, como mostra o texto de Sanches (2013, 136-147), foram desenvolvidas em Lisboa e Sevilha, respectivamente, a Casa da Guiné, Mina e Índia e a Casa de la Contratación, centralizando todos os assuntos referentes à navegação e ao comércio externo, nas quais começaram a ser produzidos, copiados e impressos os mapas que vieram a ser denominados de "Padrão Real" ou "Padrão Oficial" que constituíam uma espécie de cartografia oficial, visando ao fortalecimento do projeto político, ideológico e religioso dos Estados que a mantinham, como exemplificam a experiência histórica desde o tratado de Alcáçovas-Toledo em 1479 até ao de Tordesilhas em 1494, além da disputa pelas ilhas Molucas e a demarcação do antimeridiano, entre outros episódios, nos quais os padrões reais foram considerados como os principais documentos que os dois adversários políticos aceitavam como juridicamente válidos.

Essa sistematização cartográfica foi fundamental para a expansão dos impérios ibéricos, principalmente no Novo Mundo, pois ao passo que seus limites se ampliavam, os mapas eram instrumentalizados para servirem não somente como uma forma de orientação espacial e como um instrumento de legitimação da conquista após a incorporação de um território por meio de intervenções armadas, mas também como uma espécie de garantia de simbólica de posse.

estratégias da geopolítica até as pequenas táticas do habitar" (FOUCAULT, 1989, p. 212). Observa-se que ele, ao discutir sobre as disposições espaciais, as repartições, as espacializações, enfim, sobre as mais variadas abordagens referentes à dimensão espacial do exercício do poder, sempre o faz privilegiando os micro-espaços, tais como: a organização espacial dos hospitais, dos asilos, das escolas, dos quartéis e das fábricas. No decorrer da década de 80, os geógrafos franceses Claval (1979) e Raffestin (1993) começaram a trazer os estudos foucaultianos para o campo da Geografia. Impulsionado por essa perspectiva, Harley (2009) procura adaptar as considerações de Foucault referentes aos micro-espaços para o macro-espaço, defendendo a ideia de que as representações cartográficas sempre estiveram associadas aos grupos dominantes e estes, ao longo da história, fizeram da confecção de mapas uma das armas de inteligência especializadas para adquirir um poder, administrá-lo, codificá-lo e legitimá-lo. 
Essa associação entre o uso prático e simbólico dos mapas tornou-se indispensável para o cumprimento das aspirações expansionistas dos impérios ibéricos. O primeiro pela possibilidade de uma precisão mínima necessária para uma reinvindição/legitimação territorial, e o segundo como uma forma de exercício do poder, do poder simbólico, nos termos de Bourdieu (1989, p. 11), para quem os mapas através de sistemas simbólicos "cumprem a sua função política de instrumentos de imposição ou de legitimação da dominação"3.

Desse modo, onde o rei não se fazia presente fisicamente, nos lembra Sánchez (2013, p. 146), "não apenas se ergue um padrão de pedra em sua lembrança, mas também se representa o seu poder em forma de soberania territorial por meio de imagens cartográficas", o que quer dizer que as monarquias ibéricas, a partir do uso simbólico dos mapas, transformaram em imagem os seus ideais, ao elaborarem "mapas com palavras e discursos com mapas" durante a construção de seus impérios.

Assim, durante o expansionismo impulsionado pelas Grandes Navegações, os esforços imperiais, dos Estados organizados na Península Ibérica, para controlar o espaço, por meio das representações cartográficas, Ihes possibilitaram, tanto quanto a cruz e a espada, conquistarem o Novo Mundo de uma maneira que essa história pode ser narrada através de imagens.

\section{A reconfiguração geopolítica através dos mapas}

Ao longo do século XV, quando as principais rotas comerciais do Ocidente foram deslocas do Mediterrâneo para o Atlântico, forma-se um novo cenário internacional, cujas relações conflituosas criaram as condições para uma nova configuração geopolítica, na qual a cartografia desempenhou papel de destaque como uma ferramenta de poder para atuação diplomática dos representantes dos Estados nas disputas territoriais.

No caso de Portugal, pioneiro na expansão marítima, observa-se o quanto o seu êxito expansionista dependeu de uma série de documentos elaborados a partir do seu conhecimento cartográfico, a partir do qual foi possível a ele demacar "as divisões políticas do mundo recémalcançado", conforme explica Lopes (2016, p. 171), em meio à a competição com seu vizinho peninsular.

Assim, tanto o Tratado de Tordesilhas, como a questão das ilhas Molucas e a consequente tentativa de demarcação de uma antimeridiano cruzando o oceano Pacífico, expressam o protagonismo adquirido pela cartografia diante das disputas em torno da construção e manutenção dos impérios ultramarinos ibéricos, pois os mapas simplificaram as informações sobre uma determinada região, sintetizando o que era conhecido, compreendido, suposto ou até ignorado acerca de um determinado espaço ou território.

Esse protagonismo muitas vezes foi decisivo nas contendas entre portugueses e castelhanos, especialmente quando as suas rivalidades territoriais foram deslocadas da península para o oceano. Por exemplo, o Mare Clausum, que garantia o direito de exclusividade à Coroa portuguesa de controle das rotas do Atlântico que lhe davam acesso às ilhas por ela conquistas neste oceano, foi contestado por Castela no contexto da guerra de sucessão que neste reino aconteceu entre 1475 a 1479. No dia quatro de setembro de deste último ano, acabou sendo firmado entre as duas Coroas o Tratado de Alcáçovas-Toledo que visava acabar com as hostilidades provocadas pela referida guerra, iniciada em decorrência da morte do rei Henrique IV de Castela em 1474. Com o rei falecido, duas correntes partidárias se estabelecem reivindicando o trono de Leão e Castela: os que defendiam D. Joana, a

3 De acordo com ele, o poder simbólico é o poder de constituir o dado pela enunciação, de fazer ver e fazer crer, de se exercer pelo que ele representa, pela sua força de persuasão (1989, p. 14). 
Beltraneja, filha de Henrique (ou, segundo os mexericos da corte, da rainha,) e os defensores da infanta Isabel, irmã do rei, que acabou herdando o trono de Castela.

Com o Tratado de Alcáçovas retificado em Toledo entre Espanha e Portugal em seis de março de 1480, várias questões foram acordadas. Entre elas, a determinação de uma política referente às navegações pelo Atlântico africano e a distribuição dos territórios, conforme as zonas de influência, entre ambos os reinos. Entretanto, nesse período, Portugal já dominava, em grande parte, as ilhas atlânticas e também a costa africana. Diante da assinatura do acordo, a Coroa portuguesa, legalmente, passaria a controlar a Guiné, as ilhas da Madeira e Porto Santo, os Açores e as ilhas de Cabo Verde. Castela exerceria a sua soberania somente sobre as ilhas Canárias.

Com este e outros acordos futuros, longe de alcançar a paz final, tal Tratado levaria a uma longa e controversa disputa entre as duas potências marinhas, principalmente em relação ao Brasil, como reitera Kantor (2007), que só seria resolvida com o Tratado de Limites, não ratificado, de 1750 e formalizado em 1777 com o Tratado de São Ildefonso, de modo que se pode afirmar que ele foi determinante para a geopolítica colonial ibérica.

Por exemplo, um de seus principais desdobramentos, o estabelecimento de um paralelo ao sul das Canárias, que impedia os castelhanos de navegarem pelas águas do Atlântico, permanecendo então o princípio do Mare Clausum, deixava em aberto a livre navegação pela imensidão do Atlântico ocidental, abalando precocemente em 1493 a paz gerada pelos acordos nele firmados, com a chegada de Cristóvão Colombo ao Novo Mundo.

Essa viagem de Colombo desencadeou outra situação de rivalidades e reivindicações entre as potências ibéricas, sinalizando o fim das alianças firmadas em 1479 em Alcáçovas. A partir de 1493, inicia-se um período marcado por fortes tensões diplomáticas, gerando bulas e mapas, que se revelavam imprescindíveis para resolvê-las.

Extremamente descontente com os resultados expostos pela viagem de Colombo, D. João II enviou um embaixador para Castela com o intuito de lembrar aos Reis Católicos o Tratado de Alcáçovas (1479), alegando que Colombo tinha invadido águas portuguesas. A reivindicação do monarca português baseava-se em uma interpretação da bula Aeterni Regis, ratificada no ano de 1481. Dessa maneira, com o apoio papal, Isabel e Fernando haviam concordado que qualquer novo território descoberto no Atlântico, com exceção das Canárias, pertenceriam a Portugal. Contudo, como aponta Bown (2013, p. 141) "tratados, claro, se baseiam no princípio de que os termos permanecem válidos apenas enquanto os princípios subjacentes continuem substancialmente inalterados." Assim, os soberanos de Castela e Aragão, certos de que essas novas terras, ou a nova rota para Índias, representavam algo inteiramente diferente e imprevisto, poderiam analisá-las fora dos limites do tratado. Tal situação marcava o início de uma desgastante batalha diplomática pelas águas do Atlântico, antecipando as descobertas e as conquistas.

Buscando encontrar uma resposta para as questões levantadas pelo rei português, Isabel e Fernando, em abril de 1493, semanas depois da volta de Colombo à Espanha, solicitaram ao papa espanhol Alexandre VI a concessão das ilhas descobertas pelo navegador genovês. No mês seguinte, em favor da sua terra natal, o papa emitiu a primeira de uma série de três famosas bulas, concedendo aos Reis Católicos e aos seus herdeiros em perpetuidade, livre poder, autoridade e jurisdição de todos os tipos sobre a totalidade das novas terras, anulando o monopólio português dos descobrimentos e a possessão das Índias Orientais por completo, deixando Portugal sem os privilégios concedidos pela bula Romanus Pontifex de 1455.

Alexandre $\mathrm{VI}$, evitando um conflito ainda maior entre os reinos ibéricos, alegava que apoiava a Espanha e Portugal igualmente, deixando claro que os portugueses foram beneficiados por ele nas questões envolvendo as minas de ouro da Guiné. Entretanto, o papa, pressionado politicamente pelos 
monarcas de seu país, produziu mais duas bulas, nos dias três e quatro de maio, como se fossem extensão da bula original. A segunda das bulas alexandrinas, a Eximiae Devotionis, foi uma reformulação da primeira, enfatizando os direitos concedidos a Portugal em anos anteriores e cedendo à Espanha os mesmos direitos atribuídos ao país vizinho sobre as suas descobertas na África. Por esse motivo, a primeira bula, emitida em três de maio de 1493, carecia de argumentos mais científicos e geográficos diante da solicitação castelhana, razão pela qual o papa, recémempossado, emitiu a terceira bula no dia seguinte, legitimando, definitivamente, a propriedade dos territórios descobertos por Colombo a Castela. O novo texto era em parte uma reafirmação da primeira bula, Inter Caetera, destinado a sanar as falhas da bula anterior e a estabelecer, também, a demarcação de uma linha imaginária de polo a polo separando as águas pertencentes a ambos os reinos.

A linha citada no documento pontifício foi a base do Tratado de Tordesilhas, de forma que se a bula Inter Caetera proclamava a soberania de Castela, a seguinte definia as zonas sobre as quais esse poder soberano poderia ser exercido. Após a última bula alexandrina ser concedida em setembro de 14934, ampliando as doações à Coroa castelhana de todos os territórios asiáticos que fossem descobertos a partir do ocidente, as discussões sobre a demarcação de um meridiano, separando as possessões entre os reinos competidores ganham um novo vigor. Entre os meses que iam desde o despacho das bulas papais até o Tratado de Tordesilhas, D. João II tentou de diversas formas diminuir os impactos provocados pelos documentos expedidos por Alexandre VI. Tanto que o rei português, insistentemente, solicitava aos Reis Católicos a modificação da posição do meridiano, transladandoo mais para o oeste em relação ao que havia sido estipulado na segunda bula de maio de 1493, enquanto Fernando e Isabel organizavam uma junta cosmográfica, reunindo diversos documentos entre mapas e outros instrumentos para legitimar as suas reivindicações.

Diante disso, percebe-se o quanto os estudos cosmográficos foram determinantes na solução dos problemas políticos gerados pelas viagens de Colombo. A esse respeito, afirma-se que a carta de marear, elaborada pela equipe de Colombo para representar as ilhas descobertas, é retratada pela historiografia espanhola como um dos principais documentos utilizados no processo de efetivação do Tratado de Tordesilhas. Igualmente, para os estudiosos portugueses, os mapas produzidos por parte dos cosmógrafos do rei D. João II tiveram o mesmo peso das produções do reino vizinho. Eles alegam que grande parte das cartas confeccionadas a mando do soberano lusitano foram influenciadas pela carta de marear de Pêro da Covilhã ${ }^{5}$, enviada a Portugal ao rei em 1491 e que ela ajudou a sustentar a ideia joanina de demarcar o meridiano a 370 léguas das ilhas de Cabo Verde. Dessa maneira, de acordo com o esclarecimento de Sánchez, (2013, p. 97), a carta de Colombo e a de Covilhã "constituem um exemplo esclarecedor do que François Dainville denominou de cartografia jurídica", isto é, "aqueles mapas levantados em contexto de tensão diplomática e de litígio que foram

4 A bula Dudum Siquidem, datada de 26 de setembro de 1493, é considerada, por muitos autores, como uma reafirmação da bula Inter Caetera, de 4 de maio. Esse novo documento concedia à Espanha direito sobre todas as terras a oeste e a sul, assinalando até a Índia como terra aberta aos espanhóis. Reafirmava também que os navios de nenhuma outra nação deviam navegar, explorar ou até pescar nessas águas sem permissão por escrito, "mesmo por motivos de caridade ou fé", e que os monarcas espanhóis e português iriam mantê-las (as terras) para sempre defende-las contra quem se opusesse (BOWN, 2013, p. 152).

5 Em 1487, D. João II enviou Pêro da Covilhã, juntamente com Afonso de Paiva, para uma longa missão no oriente. Disfarçados de mercadores e treinados por cosmógrafos régios, os dois seguiram para Cairo no Egito, um dos maiores centros mulçumanos da época em busca de notícias do mítico reino de Preste João e da Índia. Pêro da Covilhã transportava com ele uma carta de marear onde teria que anotar todas as informações pertinentes dos locais em que ele estivera. Segundo vários historiadores, essa carta continha um rico conhecimento sobre os litorais da costa oriental da África e de algumas partes do continente asiático. Dessa forma, as informações levantadas por Covilhã traziam dados mais precisos e atualizados sobre essas regiões, revelando uma distância bem maior entre Europa e Ásia a partir do Oeste em relação as estimativas de Toscanelli, estudioso que influenciou o projeto de Colombo. 
utilizados como provas testemunhais em juízos ou na resolução de uma disputa geográfica", o que permite afirmar que os mapas jurídicos foram os principais argumentos materiais, exercendo a capacidade de representar o poder e os direitos de um soberano sobre os espaços conquistados.

Após as deliberações papais, as negociações entre as duas potências prosseguiram. Em março de 1494, as delegações de Portugal e Espanha reuniram-se na cidade de Tordesilhas. Depois de três meses de discussões, no dia sete de junho, os países conflitantes chegaram a um acordo histórico conhecido como Tratado de Tordesilhas. Preservando em grande parte as prescrições das bulas concedidas no ano anterior, poucos itens foram acrescentados. Entre essas novidades, ficou decidido que, dentro de dez meses a partir da assinatura do tratado, ambos os países deveriam despachar navios com especialistas em navegação e cosmografia para se encontrarem nas ilhas de Cabo Verde, com o propósito de se determinar a localização da fronteira em alto mar. Posteriormente, com a demarcação da fronteira, seria produzido um mapa, representado o meridiano separando os interesses territoriais entre portugueses e espanhóis.

No caso português, o interesse que o motivou a negociar o referido tratado foi o da localização original da linha oficial de demarcação. Insistentemente, D. João II, contestando os privilégios jurídicos concedidos pelo papa à Espanha, uniu a essa situação os seus conhecimentos cosmográficos para mudar a linha oficial mais para oeste, alegando que os navios portugueses estavam constantemente navegando por essas águas e os limites eram muito estreitos. Tal ideia, segundo Cortesão (1960 b), foi apresentada para os espanhóis como uma medida de segurança para a navegação em alto mar ao sul do Atlântico. A delegação espanhola aceitou a mudança. Entretanto, a rainha Isabel ficou bastante desconfiada mediante a solicitação do rei português. Para ela, D. João Il estava escondendo alguma informação valiosa. Era como se D. João II soubesse da existência de terras ao sul do Equador e que a sua insistência em deslocar a raia demarcatória poderia ser uma manobra para proteger seu possível descobrimento.

Consolidados os acordos, pode-se concluir que a cartografia teve um papel decisivo no desfecho dos debates pelas fronteiras do mundo a descobrir, sendo o Tratado de Tordesilhas o ápice de um processo de disputas que nos permite compreender parte considerável da geopolítica do século XVI e, no caso dos impérios ibéricos, até meados do século XVIII. Pois, aparentemente, tal tratado forneceu aos reinos competidores uma solução a uma questão complicada de se resolver e que acabou criando condições para novas disputas, porque os compromissos que foram assumidos perante os acordos assinados em 1494 geraram uma série de inconvenientes para serem debatidos. Afinal, devido à falta de um método confiável para a determinação longitudinal, o traçado de um meridiano de polo a polo não poderia deixar de acarretar a possibilidade da ocorrência de sérios problemas, como se verificou mais tarde.

Em relação a isso, cabe lembrar que a chegada de Pedro Álvares Cabral em 1500 ao território que (depois de alguns nomes) ficou conhecido como Brasil, despertaria novas discussões relacionadas ao meridiano de Tordesilhas, levando o rei Manuel I de Portugal, sucessor de D. João II, a acionar os seus cartógrafos para a elaboração de cartas e planisférios representado as terras portuguesas ao leste da linha divisória do mencionado meridiano, bem como os reis Fernando e Isabel a fazerem o mesmo ao oeste da mesma linha.

Isso permitiu confirmar a tese de que o Tratado de Tordesilhas evidenciou a verdadeira natureza dos mapas produzidos durante os descobrimentos, revelando os seus recursos retóricos e expressões autoritárias de soberania e possessão, conforme argumenta Sánchez (2013, p. 101), o que permite concluir que a representação cartográfica foi a principal ferramenta com que se fez valer a soberania de um império sobre a jurisdição territorial que marcava o seu domínio e que, em muitas ocasiões, estiveram sujeitos a fortes medidas de autoritarismo monárquico 
Portanto, grande parte dos planisférios, produzidos durante os primeiros anos do século XVI, não expressam apenas os descobrimentos. Passaram a revelar, acima de tudo, a soberania de quem os realizou, de forma que essa reorientação política dos mapas concedeu à Espanha e Portugal uma hegemonia marítima sem precedentes. Afinal, mesmo outras nações da Europa não reconhecendo o Tratado de Tordesilhas, os ibéricos, após anos de disputa, conseguiram moldar uma nova geopolítica legitimando as suas possessões por meio dos mapas, de modo que nos permite concluir, conforme observação de Ravel (1990, p. 144), que as representações euclidianas do espaço, ao serem transformadas numa paisagem física espacialmente ordenada, estavam "indissociáveis da afirmação do poder monárquico".

\section{Considerações finais}

Nesse estudo partirmos da proposição de John Brian Harley (2005 e 2009) de que os mapas são uma descrição cartográfica do mundo construída socialmente e, como tal, expressam as ideologias e as relações de poder que estão na base de sua elaboração, revelando dessa maneira, como uma linguagem não verbal, muito mais do que o espaço que se pretende por meio deles descrever.

Partimos também da proposição de Clifford Geertz (1978) de que cultura é um sistema simbólico constituído por um conjunto de valores que orientam, atribuindo sentido e dando suporte, como fatores estruturantes, à ação humana em suas mais diversas atuações na dialética da vida social.

Baseados nesses pressupostos, concebemos a cartografia como uma prática cultural que exprime os valores da época e da sociedade na qual foi produzida e das instituições e grupos sociais que a produziram, ao construir imagens do mundo que funcionam como um discurso sobre o planeta.

Assim, a produção cartográfica estudada neste estudo contribui para revelar a natureza conquistadora dos Estados Modernos, herdada do sistema de valores em que se estruturou a classe social hegemônica (a nobreza) da qual ele se originou, principalmente o seu caráter guerreiro que, como mostra Georges Dubby (1993 e 1994), configurou a sociedade medieval.

Essa herança se expressa na continuidade por eles promovida da política de extração de excedentes, por meio da conquista de terras, vigente no feudalismo. Tanto que a maioria esmagadora de suas rendas era destinada às despesas militares. No caso espanhol, por exemplo, no século XVI, $80 \%$ de seus recursos financeiros foram destinados às despesas militares, como informa Perry Anderson (1995, p. 32) que, por essa razão, (1995, p. 18) os definiu como "um aparelho de dominação feudal recolocado e reforçado", atuando dessa maneira como "a nova carapaça de uma nobreza atemorizada" pelas crises que culminaram na emergência do capitalismo.

Portanto, a cartografia pode ser considerada uma das faces dessa cultura guerreira da sociedade medieval herdada pelas monarquias ibéricas, particularmente a elaborada entre o Tratado de Alcáçovas-Toledo (1479) e a anexação de Portugal pela Espanha (1580), período em análise neste trabalho, cujos mapas, ao construírem imagens de um novo mundo que se pretendia conquistar e legitimar a posse, exprimem, como indicadores de um sistema simbólico fundamentado na guerra, a permanência da mentalidade bélica feudal (a ampliação de recursos econômicos por meio da conquista de terras) no processo de expansão territorial dos Estados Modernos.

Além disso, a cartografia, como parte desse processo, foi também um instrumento estratégico para a viabilização de tais objetivos expansionistas, tanto como recurso técnico destinado à orientação das movimentações por terra e mar de navegantes e tropas, quanto instrumento, dotado 
de um eficiente poder simbólico, fundamental para o embasamento do direito de posse nos litígios diplomáticos da geopolítica de uma época dinamizada por grandes descobertas geográficas.

Desse modo, tanto quanto a cruz e a espada, os mapas funcionaram como armas nos processos de conquista, criando condições para a atuação estatal organizar expedições e legitimar as suas conquistas no concerto das nações, funcionando dessa forma como um esteio do fortalecimento do poder monárquico para a construção de seus impérios.

Impérios cujas histórias se revelam, como uma narrativa de imagens, na sua produção cartográfica, que foi convertida em uma das ferramentas mais eficientes na dialética da geopolítica internacional do alvorecer da Idade Moderna, sendo a experiência portuguesa, nação pioneira nas grandes viagens oceânicas, um dos melhores exemplos de sucesso dessa conversão, ao lhe permitir expandir seu território, consolidar suas posses e ampliar o seu poder em um mundo cujas estruturas estavam em acelerado processo de transformação.

É isso, portanto que, no título desta pesquisa, chamamos de cartografia da conquista, isto é, um conjunto de operações técnicas utilizadas para a representação gráfica da superfície terrestre, da qual os Estados Modernos, especialmente os estruturados na Península Ibérica, se valeram para a condução de suas políticas de expansão marítima e territorrial no tempo das Grandes Navegações. 


\section{Referências}

ALENCASTRO, L. F. de. (1998) A Economia Política dos Descobrimentos. In: Adauto Novaes (Org.). A Descoberta do Homem e do Mundo. São Paulo: Companhia das Letras, p. 193-207.

ANDERSON, P. (1995) Linhagens do Estado Absolutista. $3^{a}$ ed. São Paulo: Brasiliense.

BARRETO, L. F. (1983) Descobrimentos e Renascimento: formas de ser e pensar nos séculos XV e XVI. Lisboa: Imprensa Nacional/Casa da Moeda.

BLACK, J. (2005) Mapas e Histórias: Construindo Imagens do Passado. São Paulo: EDUSC.

BOURDIEU, P. (1989) O Poder Simbólico. Rio de Janeiro: Bertrand Brasil.

BOWN, S. R. (2013) 1494. São Paulo: Globo.

BOXER, C. (2012) O império marítimo português: 1415-1825. Tradução de Inês Silva Duarte. $2^{\mathrm{a}}$ ed. Lisboa: Edições 70.

BROTTON, J. (2012) Uma história do mundo em doze mapas. Rio de Janeiro: Zahar, 2012.

BUESCU, A. I. (2008) D. João III. Lisboa: Círculo de Leitores.

CANAS, A. C. (2003) Cartografia náutica portuguesa. Lisboa: Instituto Camões.

CHARTIER, R. (2002) A História cultural - entre as Práticas e Representações. $2^{a}$ ed. Rio de Janeiro: Difel.

CLAVAL, P. (1979) Espaço e Poder. Rio de Janeiro: Zahar.

CORTESÃO, A; MOTA, A. T. da. (1960 a) Portugaliae Monumenta Cartographica. Lisboa: Comissão para as comemorações do V centenário da morte do infante D. Henrique, Vol. 1.

CORTESÃO, J. História do Brasil nos velhos mapas. (1960 b) Lisboa: Imprensa nacional-Casa da moeda.

DUBY, G. (1994) As Três Ordens, ou o Imaginário do Feudalismo. 2ª ed. Lisboa: Estampa.

DUBY, G. (1993) Guerreiros e camponeses: os primórdios do crescimento econômico europeu, sécs. VII-XII. $2^{\text {a }}$ ed., Lisboa: Estampa.

DUTRA, D. P. (2013) A cultura dos descobrimentos em Portugal: um estudo da relação entre a Sabedoria do Mar e o Conhecimento Acadêmico na Renascença. Niterói: Dissertação (Mestrado em História), Departamento de História, Universidade Federal Fluminense.

FOUCAULT, M. (1989) Microfísica do Poder. $8^{a}$ ed. Rio de Janeiro: Graal, 1989.

FURTADO, J. F. e SILVA, V. F. (2017) The cartographic challenge of the new. Belo Horizonte: Odisseia. GEERTZ, C. (1978). A interpretação das culturas. Rio de janeiro: Jorge Zahar.

GODINHO, V. M. (2007) A expansão quatrocentista portuguesa: problemas das origens e da linha da evolução. Lisboa: Dom Quixote.

HARLEY, J. B. (2009) Mapas, saber e poder. Confins, n. 5, 2009, p 1-25, [Online], http:// confins.revues.org/index5724.htm. Acesso em: 27 dez. 2018.

HARLEY, J. B. (2005) La Nueva Naturaleza de los Mapas. Ensayos sobre la historia de la Cartografia. México: Fondo de Cultura.

HARVEY, D. (1992) Condição Pós-Moderna. São Paulo: Edições Loyola.

JACOB, C. (2016) Por uma história cultural da cartografia. Espaço e Cultura, Rio de Janeiro, n. 39, p. 221-236.

KANTOR, Íris. (2007) Usos diplomáticos da ilha-Brasil: polêmicas cartográficas e historiográficas. In: Vária História, Belo Horizonte, v.23, n. 37, p. 70-80.

LESTRINGRANT, F. (2009) A oficina do cosmógrafo ou a imagem do mundo no Renascimento. Tradução de Edmir Missio. Rio de Janeiro: Civilização Brasileira. 
LOPES, J. F. R. (2016) Cartografia histórica e geopolítica do espaço brasileiro no contexto da colonização da América do Sul (séculos XVI-XVIII). Tese (Doutorado em Geografia) - Instituto de Geografia e Ordenamento do Território, Universidade de Lisboa, Lisboa.

QUADROS, E. (2008) A letra e a linha: a cartografia como fonte histórica. Mosaico, v. 1, n. 1, p. 27 - 40. RAFFESTIN, C. (1993) Por uma geografia do poder. Trad. de Maria Cecília França. São Paulo: Ática. REVEL, J. (1990) A invenção da Sociedade. Rio de janeiro: Bertrand Brasil, 1990.

SÁNCHEZ, A. (2013) La espada, la cruz y el Padrón. Soberanía, fe y representación cartográfica en el mundo ibérico bajo la Monarquía Hispánica (1503-1598). Madrid: Consejo Superior de Investigaciones Científicas.

SERRÃO, J. V. (1995) Lusitanidade e Hispanidade: Realidades pioneiras na formação do Estado Moderno. Mare Liberum, no 10, Lisboa, p.13-19.

THOMAZ, L. F. (1998) De Ceuta a Timor. 2 ed. Lisboa: Difel. 